\title{
In the Classroom
}

\section{Progress in Practice: Bookends and Boilerplate}

I. Vigilance for the Obligations for Scholarship in Chemical Education

BRIAN P. COPPOLA

The University of Michigan

Ann Arbor, Ml 48109-1055

bcoppola@umich.edu

Since the early

1990s, two

significant

changes have

impacted the

look of proposals

in chemical

education.

Individuals involved in curriculum design often introduce new, modified, or applied ideas about instruction that span from classroom methods to philosophies of education. In this series, we examine progress in chemical education that is related to actual practices, and where many recommendations have originated from areas in higher education that exist alongside of and overlap with chemistry. Rather than an exhaustive review, we will select examples, background, and vocabulary that may either invite interested newcomers to explore a different area in their teaching, or provide language and precedent for individuals who wish to contextualize ideas they have developed independently. 
are thinking about an area of inquiry or its development. The premise is valid regardless of the fact that proposal writers will conform to what they perceive to be the spirit and letter of a Program Announcement because these guidelines are also representative of the thinking of a comparable group. The context of my analysis is my participation as a member of various review and discussion panels (primarily for the NSF) over the last six years.

Since the early 1990s, two significant changes have impacted the look of proposals in chemical education. Both of these changes, in principle, have been productive. First is the need to include the intellectual context or background for a proposed activity. Borrowing appropriately from the culture of laboratory research proposals, the desired outcome is for projects that are "informed by" current thinking and the experiences of others. Second is the need for assessment and evaluation that has become widespread through public and private funding, lately reflecting the popular distinction between materials used for periodic documentation of progress (formative) and those used to make decisions of judgment (summative).

My observation and concern is the ease with which these two changes, providing intellectual context and assessment-evaluation results, do not inform projects nor are informed by them, respectively. Instead, like bookends and boilerplate, the intent of these changes can remain disintegrated from the proposed project, physically surrounding it, yet remain as traditionally disconnected as ever. The letter of the law is satisfied, but its spirit is lost, circumvented, or at least misunderstood. Fundamentally, the existing standards for precedent in scientific writing and for what constitutes evidence make for an excellent departure point for this discussion. At this point in my own essay, however, I now approach the edge of the gray area. I cannot cite the written materials (unfunded proposals), neither can I recount specific examples or reveal information about which I have committed myself to confidentiality. Although funded proposals are in the public domain, I am not inclined to specifically mention some projects rather than others because it would draw unintended attention to them. Still, the general principle is as important to implementing actual projects and writing publications as to the analysis of the proposals on which this analysis is based, so the concepts can be examined broadly. During the preparation of this manuscript, a representative of the NSF directed me to a new publication from the Division of Education and Human Resources, NSF-97-83: A Guide for Proposal Writing, in which a number of these same concerns have been raised. Interested readers are directed to 
the NSF site on the World Wide Web for more about this and other useful information (available URL: http://www.nsf.gov).

Conceptually, the intellectual context of a proposed study should provide the anticipated audience with a critical examination of enough of the available background as it pertains to the proposed work, in order to achieve:

1. A realistic case for the proposed work to be seen as a rational conclusion or extrapolation from the precedents, but not to overwhelm the information with a survey of the general topic.

2. Evidence of a thoughtful examination of the prior work. A previously published study might contain the right keyword or have attempted to address the desired topic, but this does not constitute scholarly evidence. An author should be able to defend the inclusion of every source cited, including an understanding of the manuscript, its implications, and the specific results and rationale that impact their use in the current project.

3. A rational discourse on alternatives, conflicting perspectives, design limitations and other defensible (or sometimes even indefensible) viewpoints. As above, projects are typically narrow enough in focus to keep this from becoming an exhaustive review but rather should be confined to outcomes that impact the specific project being proposed.

The following categories are representative of the problems I have encountered, as a reviewer, related to the generation of intellectual context in a proposal. These are based on seeing enough examples to think these categories provide generically useful guidelines for examining one's writing. Although individual proposals were used to generate these impressions, only examples I encountered at least twice are used to illustrate any one point, so no individual's project is implicated nor should be inferred. The five categories are not at all orthogonal, either, so the examples have been selected based on their ability to best illustrate the point.

\section{Unadapted transfer from another context}

If a program has been demonstrated to be successful in one context, it is not necessarily true that it will be so under a different set of conditions. Laboratory 
chemists recognize this as an intrinsic feature of working with substances (organic chemists might call it the "methyl versus ethyl" effect). Operationally, in the laboratory, we seek careful distinctions between the general phenomenon (substitution reactions, for example), and the contextually mediated (structural) differences. Equally so in instruction. What is appropriate, in concept and in practice, for high school students may not be valid for college students. A program that is successful for the undecided or uncommitted science student (for instance the American Chemical Society's Chemistry in Context or Chemistry in the Community ) may not immediately transfer to the population of science-motivated students; the basic operational context (students who are unmotivated to take science courses) is not valid. This "structural" question needs to be raised and addressed in the context of a proposal so that it is also considered in the design and implementation of the project, as well as to become a topic of discussion by others. How does a basic message from a proposed activity (or methodology) that is being transferred need to adapt to the constraints of a different context to be successful?

What adaptations have to be made to the excellent living-learning programs that were originally designed for at-risk students when they are attempted with students who are not at risk? What's good for the goose is not necessarily good for the gander. The same thing is true, I think, for the wholesale importation of group learning into classrooms. The most powerful antecedents for this movement are in the elementary education literature; what understandings of college students in general, and then college students in your own context, and then college chemistry students in your course, are being brought to the table to inform the development of any group activities?

\section{Unexamined assumptions}

The title of this category is self-explanatory. Sometimes the basis of a project is stated as a given, and then the architecture that it presumes is constructed. Sometimes the "given" is not so given. Many projects in the last few years have based curriculum development on the idea of modules. While the written arguments for modular instruction can be strikingly and intuitively appealing for instructors, and even for students who may desire less interdependent learning between topics, to the best of my knowledge there is no compelling body of literature that supports modular instruction as an effective way for students to develop high-order skills. I openly invite a contribution to this Series to provide the kind of background about modular instruction 
that would create a compelling basis for its development in college teaching and learning. This is not a criticism of modular instruction; it is a statement about the design of proposals.

\section{Pluralistic beliefs}

Pluralistic beliefs are somewhat like urban myths. If "everyone knows" something to be true, or it falls under the category of conventional wisdom, then it will remain unexamined. In my recent experience, there are a few recurring examples of this. First, that instruction in small groups is good because instruction in large classrooms is bad. Second, that the introduction of a computer or other new technology-mediated version of an existing instructional design will be naturally motivational. Third, that a capstone experience in an area previously disintegrated from chemistry, one that needs to be reintroduced into science education, will accomplish its goal. Specifically, and sometimes in spite of clear experiences to the contrary, history or philosophy of science courses are offered with the intent to impact students' understanding of science, courses in scientific ethics seek to impact scientific practice, and programs operating with the "role-model" assumption for gender and ethnicity hope to impact critical behaviors related to discrimination, diversity, recruitment, and student learning. At least many believe so. None of my examples is meant to argue against them as important topics, but it does call into question the relationship between isolated courses and synthetic thinking about an entire subject, something that we already criticize in the structure of the traditional chemistry content courses themselves.

\section{Unattached literature survey}

Some proposals, in order to reply to the need for intellectual context, are written like some of the answers we get from our students: the authors tell us everything they know about a subject and leave it to the reader to make the connection between the question and the answer. If the proposed work does not appear until the eighth or tenth page of a 15-page proposal, too much background information is probably being provided. Whenever I propose to examine something, there are always increasingly large concentric bodies of information in which the subject is embedded. If I am writing a proposal to examine the synthetic methodology of azomethine ylides (an example of a 1,3-dipole used to make alkaloids), I am not going to write reviews of both 1,3-dipolar 
cycloaddition chemistry and alkaloid synthesis. I will probably provide the contexts in which azomethine ylides arise, and then compare and contrast my proposed application with the closest alternatives, providing commonalities and differences and, naturally, the anticipated advantages of my plan relative to other options. If I am adapting an active learning strategy into a specific kind of classroom context, then I am much more interested in the selection of this strategy relative to others and the advantages it will bring than I am a long generic discourse on active learning. The most disconnected version of literature surveys that I have seen is what one might call "the top 15 cited articles from the Journal of Chemical Education" that are related to chemical education research. Regardless of the applicability of the references to the proposed work, and with increased frequency, an author's obligation to provide readers with an intellectual context (and to demonstrate background understanding) is attempted to be satisfied with a standard set of "chemical education research" papers.

\section{Wish fulfillment}

The larger the claim, the more responsibility there is to acknowledge and take on the proposed scope explicitly. Is a materials science context being created if the proposal is a series of materials science examples in a traditional context? What does it mean to construct a biological context if it looks like the traditional syllabus using biological examples? If the first two years of an introductory program are proposed to become an integrated view, then what of a plan than still identifies the "organic chemistry unit" and the "analytical chemistry lab"? Saying or writing a thing does not make it so. The reader who is excited by the promise of a high-level goal will be especially disappointed when "the walk" does not match "the talk". A more accurate description of plan that is congruent with the plan itself, even if it does not sound as elegant, will have more integrity.

It is in the best interests of chemical education to anchor work within the discipline, but then to draw from work outside of chemistry when it impacts or informs the general design of projects. Within the guidelines suggested in this article, one should still seek out and understand successful design that has been developed outside of chemistry and then work to do what that practitioner cannot: translate that success into the context of chemistry learning because of your understanding of chemistry. Many examples (both good and bad) of adopting case study methods, group learning methods, and computational learning environments into new subject areas exist. Many 
times, familiar tasks are simply redone in a new format (e.g., "Do problems 6-10 in groups rather than by yourself"). This does not take anything about the context into account. These tasks can be productive; productivity is not the issue. The point is that subject matter and student populations are not neutral mediators, so it is not enough to find interesting ideas outside of chemistry and to assume that they will work under a different set of conditions or assumptions. Examples are more rare where the format has driven the adapter to invent new kinds of tasks that take advantage of what the format offers within the specific subject. In other words, a series of questions needs to be answered during the translation process: Why will the project work? Why will the project work in chemistry? Why will the project work in college-level chemistry (majors or non-majors)? Why will the project work in college level chemistry (majors or non-majors) at my institution (and what are the issues related to other institutions and populations)? The answers to these questions would help the readers and writers of proposals alike, and extrapolate easily to benefits in actual implementations as well as the eventual modifications and dissemination.

As much as the standards for precedent and argument can be specifically modeled by standard practice in science, the approach to assessment and evaluation cannot. The whole area of assessment in postsecondary, discipline-centered learning is unformulated enough to call for patience and experimentation. Yet, there are guideposts, and progress will arise from understanding what already exists rather than what does not. In order to give this important topic its due focus, I will take it up separately in the future. 